\title{
Unmet Needs to Treat Schistosomiasis in Children Under Five Years Old in uMkhanyakude District of KwaZulu-Natal, South Africa
}

\author{
Mhlengi V. Ncube ${ }^{1}$, Innocent T. Mutero ${ }^{1} \&$ Moses J. Chimbari ${ }^{1}$ \\ ${ }^{1}$ School of Nursing and Public Health, College of Health Sciences, University of KwaZulu-Natal, Durban, South \\ Africa \\ Correspondence: Mhlengi Vella Ncube, School of Nursing and Public Health, College of Health Sciences, \\ University of KwaZulu-Natal, Durban 4001, South Africa. Tel: 27-079-351-1250. E-mail: \\ mhlengivncube@yahoo.com
}

Received: August 13, 2019 Accepted: September 18, 2019 Online Published: March 30, 2020

doi:10.5539/gjhs.v12n4p127 URL: https://doi.org/10.5539/gjhs.v12n4p127

\begin{abstract}
Preventive treatment for schistosomiasis control is a priority objective for the Department of Health (DoH) in South Africa. The uMkhanyakude district of KwaZulu-Natal is one of the districts in which schistosomiasis in a major public health concern. We mapped the unmet resource requirements for a schistosomiasis control mass drug administration (MDA) program targeting children aged five years old and below in the uMkhanyakude District. We interviewed 10 decision makers among the uMkhanyakude Health District staff in order to understand the resources that the district has and the resources that the district needs to implement a schistosomiasis control MDA program targeting children aged five years old and below in the uMkhanyakude district. We analyzed and reported on the resources based on the following categories: financing; coverage; program integration; monitoring and evaluation; infrastructure; materials; human resources and training. We identified the resources that the district has and the resources that the district needs to acquire to implement a schistosomiasis MDA program targeting children aged five years old and below. The resources that the district needs to acquire to implement a schistosomiasis control MDA program for children under five include but are not limited to financing, human resources and digital scales. The uMkhanyakude district has insufficient resources to implement a schistosomiasis control MDA program targeting children aged five years old and below. The cost of the resources that need to be acquired for the program could be reduced by integrating the schistosomiasis control MDA program with existing child health intervention programs for children aged five years old and below. Economic evaluations are necessary to determine the child health program to which the schistosomiasis control MDA program could be most cost-effectively integrated to.
\end{abstract}

Keywords: Schistosomiasis, Mass drug administration, children aged five years old and below
Abbreviations
CCG: Community Care Giver
DoH: The South Africa Department of Health
ECD: Early Childhood Development
IMCI: Integrated Management of Childhood Illnesses
LMIC: $\quad$ Low and Medium Income Countries
MDA: Mass Drug Administration
NHLS: National Health Laboratory Services
NTD: Neglected Tropical Diseases
PZQ: Praziquantel
SCI: $\quad$ Schistosomiasis Control Initiative
STH: Soil Transmitted Helminths
TB: Tuberculosis 
UKZN: University of KwaZulu-Natal

WBOT: Ward Based Outreach Teams

WHO: World Health Organisation

\section{Background}

Recent evidence shows that infants living in schistosomiasis endemic areas may be infected by schistosomiasis in their first year of life, contrary to beliefs that children under five are not at risk of infection (Stothard, Sousa-Figueiredo et al., 2013). Global estimates show that 50 million children aged below five years are at risk of contracting schistosomiasis (WHO, 2011; Osakunor et al., 2018). To date there is no vaccine against schistosomiasis(Tebeje, Harvie et al., 2016). In the absence of a vaccine, mass drug administration (MDA) has been found to be a cost-effective strategy to prevent and control schistosomiasis in endemic regions(WHO, 2018). Five years old children and those below that have previously been excluded from schistosomiasis control MDA programs. In response to evidence showing that this age group is at risk of contracting schistosomiasis, WHO has recommended the inclusion of children aged below five in schistosomiasis control MDA programs in endemic areas (Stothard, Sousa-Figueiredo et al., 2013). Operational planning based on the resources that are available is important to ensure the success of MDA programs (Babu \& Kar, 2004, Sturrock et al., 2011).

Operational resources for schistosomiasis control MDA programs differ with each country and target population. For example, in the Koome Islands of central Uganda, Village Health Team members went house-to-house or used gatherings to distribute PZQ treatment(Tuhebwe et al., 2015), while in Burundi mobile clinics, health facilities and schools were used (Ndayishimiye et al., 2014). The composition of the human resources, and the implementation strategies for the schistosomiasis control programs in the two countries were different (Ndayishimiye et al., 2014; Tuhebwe et al., 2015). This shows that the program requirements of programs will differ between countries.

The WHO recommends that an PZQ mass drug administration for children aged five years and below should be implemented in a healthcare establishment such as a clinic (WHO, 2018). WHO further recommends that such an MDA program must be integrated with existing preventive child health programs (WHO, 2018). Program integration has been found to be cost effective based on determinations of economies of scope (Turner et al., 2017). Clinical considerations are however necessary to establish the pharmacological implications of preventive treatment program integration (de Souza \& Dorlo, 2018).

The World Bank recommends local financing and ownership of mass drug administration programs(WHO, 2015). In Burundi, for example, the Ministry of Health was responsible for a preventive treatment program for schistosomiasis and soil transmitted helminthes program for children aged 1-14 years old (Ndayishimiye et al., 2014). Children aged below five years were, however, only treated for STH but not for schistosomiasis (Ndayishimiye et al., 2014). Leaders in schistosomiasis control, such as the Schistosomiasis Control Initiative (SCI), with extensive experience in implementation of schistosomiasis programs in Africa can be approached for additional information on how best to use existing healthcare resources to conduct a schistosomiasis program for any age group in rural communities (Savioli et al., 2017).

The South Africa National Department of Health Strategic Plan for 2014/2019 reports that Neglected Tropical Diseases are endemic in South Africa and recommends the prevention approach to fight these diseases (NDoH, 2014). The DoH, therefore, intends to implement a mass drug administration program targeting affected populations nationwide, especially school children in the year 2020 (Health, 2019). The inclusion of children aged five years old and below in this MDA program will be important for reducing transmission and safeguarding the health and early development of these children(Stothard et al., 2013). The uMkhanyakude Health Plan for 2018/2019 - 2020/2021 mentions schistosomiasis as one of the public health challenges in the district (KZN-DoH, 2018). This presents an opportunity to include children aged five years and below in treatment programs.

When preparing for an MDA program or any other healthcare intervention, it is important to take into account the resources that are available and to have knowledge of existing intervention programs (Marchal et al., 2011). Managers of healthcare systems have the responsibility for ensuring the best use of available healthcare resources (Marchal et al., 2011). The objective of this study was to identify the additional resources that could be required to implement a schistosomiasis control mass drug administration program for children aged below five years old by primary healthcare facilities in areas that are affected by schistosomiasis in South Africa and similar countries, using the uMkhanyakude Health district as a case study. We explored the perspectives of the child healthcare programs decision makers within the uMkhanyakude health district staff on the resources considerations for implementing a schistosomiasis control MDA program for children aged five years old and below. The resource considerations were in relation to financing of the program, achieving the required treatment coverage, program 
integration, monitoring and evaluation, infrastructure, materials, human resources and training of personnel. The financing theme was selected because funding for schistosomiasis is a challenge in most of the affected countries (Reed \& McKerrow, 2018).Treatment coverage and program integration themes were selected because both form part of the WHO strategy for the control of neglected tropical diseases including schistosomiasis (WHO, 2006; WHO, 2018). Monitoring and evaluation is important is important in order to determine whether or not an MDA would have achieved the desired impact (Webster et al., 2014). The training theme emerged from the interviews that we conducted with the healthcare staff.

\section{Method}

\subsection{Study Setting}

This study was conducted in the uMkhanyakude District of KwaZulu-Natal because schistosomiasis is a public health challenge in this district (KZN-DoH, 2018). Administratively, the district has four local municipalities: Jozini, uMhlabuyalingana, Big 5 Hlabisa, and Mtubatuba (Municipality, 2018). The uMkhanyakude district is serviced by 5 district hospitals that are supported by 52 provincial clinics (KZNHealth, 2018). Several healthcare programs are implemented through these hospitals and clinics including those for children below the age of five.

\subsection{Study Design}

Designed as a case study of uMkhanyakude District, this research followed a qualitative approach to collect empirical data using interviews conducted with health staff members who worked for the uMkhanyakude District Department of Health.

\subsection{Study Population}

All the study district health staff members were part of the uMkhanyakude District Department of Health at the time that the study was conducted. We preselected them using the uMkhanyakude Health District website (KZNHealth, 2018). Out the 20 specialists that we identified, we purposively selected 9 district health staff whose roles included decision making in the interdisciplinary healthcare delivery for children aged below five years. We identified an additional district health staff member based on their involvement in existing studies that members of our research team are part of, thus making a total of 10 pre-selected district health staff members. We interviewed 9 out of the 10 district health staff members because one was not available. Additional three district health staff members were recommended for interviews by some interviewees. Of these three, one was available. Thus, ultimately, we interviewed 10 district health staff members; 7 females and 3 males. All the district health staff members had served the uMkhanyakude Health District for at least 24 months. The roles of all the district health staff members included decision making, training, advisory and implementation of healthcare programs. The minimum academic qualification of the district health staff members was a Diploma level qualification. To ensure the confidentiality of our participants, the district health staff members' roles and job titles are masked in this study.

\subsection{Data Collection and Analysis}

We conducted semi-structured individual interviews between December 2018 and January 2019 at venues agreed upon by the district health staff members or telephonically depending on the convenience of the district health staff member. We asked similar questions regarding implementation of a preventive schistosomiasis treatment program for children aged below five years. The questionnaire had the following 3 themes: 1 . Existing healthcare programs for children under the age of five years, 2 . Activities involved in treating schistosomiasis in children aged below five years; and 3. Integration of a schistosomiasis treatment program into existing programs targeting children aged below five years. The district health staff members maintained the right to disregard questions that they felt were irrelevant to them and were also allowed to provide additional information that they deemed important but not included in the pre-determined questions. We recorded the discussions using a voice recorder and made handwritten notes according the following themes: financing; coverage; program integration and monitoring and evaluation. Training was included as an additional theme because district health staff consistently mentioned training during interviews. We selected quotes from the participants that best suited the themes that we reported on.

\subsection{Triangulation and Validity}

Validity was ensured through using purposive sampling to select respondents who are in a strong position to speak on issues relating to treatment program development, healthcare program resource planning and decision making in the uMkhanyakude Health District in KwaZulu-Natal. The participants had worked in their roles for at least two years and had tertiary level qualifications. In addition, the data collection instrument was informed by the WHO Needs Assessment Tools (WHO, 2000). 


\subsection{Ethical Clearance}

Ethical clearance was obtained from the University of KwaZulu-Natal Biomedical Research Ethics Committee (reference number: BE403/18) and the KwaZulu-Natal Department of Health Research Committee (reference number NHRD_201809_007).

\section{Results}

\subsection{Financing}

The district health staff members considered financing to be important in the implementation of child health programs such as a schistosomiasis control MDA program for children aged five years old and below emphasizing that money spent on an intervention must be informed by the epidemiology of the disease (Table 1). A district health staff member told us that:

"Epidemiological considerations must be taken into account when we decide on our budget."

The district health staff members mentioned financial constraints in implementing some programs and found the intervention of some Non-Governmental Organizations (NGOs) helpful in the provision of adequate resources to ensure the success of treatment programs. Financing of the HIV/AIDS program was given as an example of a well-funded program that includes child health intervention. The district health staff members recommended the need to secure more partnerships to finance healthcare programs in the district including child health programs.

\subsection{Coverage}

District health staff members stated that the coverage of child health programs in the district is heterogeneous. Some district health staff members told us that the vaccination program is one of the most successful child health programs in the district. One of the district health staff members said to us:

"When it comes to the vaccinations of the children under five years old we are on target."

Some district health staff members thought that the vaccination program was successful because parents were keen on the program.

The deworming program was given as an example of a program with poor coverage in the district. Some of the interviewees thought the poor coverage was a result of lack of interest from parents. The participating district health staff members recommended that health education could be key to achieving sufficient treatment coverage and that this would apply to a schistosomiasis control MDA program for children aged five years old and below. They stressed the need to ensure that correct information reaches communities; especially information on the side-effects of different treatments (Table 1). One of the district health staff members encouraged strong health collaborations with traditional leaders so that the correct information could be associated with individuals that the communities trust. This district health staff member to us that:

"It is important of us to work with the traditional leaders. Some of our health education activities are done during meetings which the indunas hold with the communities."

\subsection{Program Integration}

The district health staff members/participants supported the concept of integrating the schistosomiasis control MDA program for children aged five years old and below with existing child health programs. A district health staff member informed us that from a patient or a guardian of a minor's perspective, fragmented treatment programs take up alpatient time. This district health staff member told us that:

"Program integration saves the guardians/parents' time and the children will receive better holistic care."

The district health staff members suggested that the deworming and vitamin A supplementation program was the most appropriate to integrate with schistosomiasis MDA program for children aged five years old and below. The reason given by the district health staff members was that parents are increasingly getting to know the program.

One district health staff member was unsure about the impact of the period of none activity in the vaccination program between the ages of 18 months and 60 months. The district health staff member was also undecided between whether the gap provides an opportunity to insert the schistosomiasis MDA program or whether that gap would make it difficult for people to avail their children to the schistosomiasis MDA program (Table 1).

One district health staff member had reservations with integrating the schistosomiasis MDA with the deworming MDA for this age group because of the insufficient treatment coverage of the deworming program. 


\subsection{Monitoring and Evaluation}

The district health staff members indicated that there is an existing strategy that could be adopted for use in the PZQ MDA program children aged five years old and below. This monitoring system is currently used to manage incapacitated patients receiving treatment at home. One district health staff member told us that:

"... all patients that are treated at home are linked to a facility that is near the homestead."

Children can be linked to a clinic facility near their homestead to manage side-effects. The district health staff members opined that the communities should be educated on how to observe and seek help in the event of adverse effects to PZQ experienced by the children. One district health staff member suggested that an adverse events reporting form that is specific to the schistosomiasis control MDA program for children aged five years old and below could be developed for use by the nurses in the clinics when side-effects are reported.

The district health staff members also suggested compliance can be monitoring through continuous auditing of the child health booklet so that any child who misses treatment is easily identified treatments. They recommended that PZQ should always be available at clinics so that children who are identified as having been missed by the MDA program can receive their PZQ dose when they visit any clinic or participate in any clinic based child health program.

\subsection{Infrastructure}

District health staff members said they were happy for the 52 clinics spread throughout the district as well as the crèches and ECD to be used during schistosomiasis control MDA for children aged five years old and below.

"The vaccination program is already running in the clinics. The deworming and vitamin $A$ is done in the crèches that are registered with the Department of Social Development and ECD centres."

The district health staff members were of the view that some of the resources that are available in the clinics or for use when treatment teams go to crèches and ECD centres could be availed to the schistosomiasis control MDA program for the children aged five years old and below in the district.

\subsection{Materials}

Some of the district health staff members informed that the district has a collaborative health education system that involves the district health department, the district municipality and the department of social services. One of the district health staff members informed us that the community radio stations in the district are also forthcoming in offering air time for health education to be done on their radio stations. These district health staff members told us that although transport and materials for health education are available for existing health programs, health education pamphlets, posters and information for a schistosomiasis MDA program targeting children aged five years old and below are not available.

When asked about the presence of resources that could be used during the treatment process, some of the district health staff members informed us that the district health department has allocated weight scales and measuring boards to every healthcare facility. These district health staff members informed us that the district health department also buys additional weight scales to replace those that get irreparably malfunctioned. The district health staff members also told us that at times the backup scales run out due to financial constraints and these may take a while to replace. We were informed by a key district health staff member that pestle and mortars for crushing tablets have been used in one of the treatment programs in the district that included children aged five years old and below.

Some of the district health staff members informed us that food in the form of micronutrient supplemented instant porridge is available to all the clinics in the district through the health district's nutrition program. They informed us that this porridge can be fed to the children during the treatment program if need be. A district health staff member informed us that this porridge is also availed to children in crèches and early childhood development (ECD) centres that are registered with the Department of Social Development DoSD.

\subsection{Human Resources}

District health staff members suggested that the implementation of a schistosomiasis control MDA for children aged five years old and below should be done by the ward based outreach teams (WBOTs) who are spread throughout. A district health staff member said:

"The WBOT, ward based outreach team, are the best people to go out and implement the schistosomiasis treatment program. They already do that with the other programs."

The WBOT consist of a professional nurse, a staff nurse, and CCGs. The interviewees thought the CCGs are 
effective in implementing healthcare intervention but are insufficient to cover the needs of several programs. The respondents also said the high turnover of CCGs was because the current hiring policy stipulates that CCGs must be employed for 12 months on a rotational basis could negatively affect the quality management of treatment interventions. Consequently, some interviewees recommended longer term employment contracts for the CCGs (Table 1).

\subsection{Training}

Interviewees were of the opinion that some of the activities that we identified to be necessary to implement a schistosomiasis control MDA program for children aged five years old and below are similar to those involved other child health programs. The district health staff member informed us that for example, the CCGs are well trained in activities such as measuring the weight and height of children which are important in determining the PZQ dosage that has to be given to the children. In addition, nurses are trained to administer treatment based on the essential medicines list (EML) and guidelines are provided in the EML for the treatment of isolated cases of schistosomiasis in children between the ages of 24 months and 59 months. The district health staff members recommended that, to ease fiscal constraints, the training for the implementation of a schistosomiasis control MDA program targeting children aged five years old and below could be appropriately integrated with existing training programs. One of the district health staff members said:

'The CCGs have been trained on how to measure the weight and the height of the children, but they have not been trained to plot graphs in road to health booklet. Only the nurses can do that.'

One district health staff member recommended that schistosomiasis treatment for children aged five years and below could be integrated with the program on Management of Childhood Illnesses training (Table 1).

Table 1. Available operation resources and needs for implementation of a schistosomiasis control MDA program for children aged five years old and below in uMkhanyakude

\begin{tabular}{|c|c|c|}
\hline Theme & Available resources & Unmet Needs \\
\hline \multirow{2}{*}{ Financing } & \multirow{2}{*}{ None. } & Epidemiological data. \\
\hline & & Partnerships or Collaborations. \\
\hline \multirow{2}{*}{ Coverage } & \multirow{2}{*}{ Health Promotions Office. } & Health education. \\
\hline & & Buy in from parents. \\
\hline \multirow{4}{*}{ Program Integration } & $\begin{array}{l}\text { Support from district health staff } \\
\text { members. }\end{array}$ & \multirow{4}{*}{$\begin{array}{l}\text { Decision on which program to integrate } \\
\text { the schistosomiasis control MDA of } \\
\text { children aged five years old and below } \\
\text { with. }\end{array}$} \\
\hline & Vaccination Program. & \\
\hline & Deworming and Vitamin A & \\
\hline & Supplementation program. & \\
\hline \multirow{2}{*}{ Monitoring and Evaluation } & Monitoring system for side-effects. & \multirow[t]{2}{*}{ Laboratory diagnosis evaluation. } \\
\hline & Monitoring mechanism for compliance. & \\
\hline \multirow[b]{2}{*}{ Materials } & \multirow[b]{2}{*}{$\begin{array}{l}\text { Weight scales, measuring boards, } \\
\text { micronutrient porridge. }\end{array}$} & Additional weight scales, \\
\hline & & $\begin{array}{l}\text { Additional micronutrient porridge, } \\
\text { pestle and mortar, pamphlets and } \\
\text { posters. }\end{array}$ \\
\hline \multirow{3}{*}{ Infrastructure } & Clinics & \multirow{3}{*}{ None } \\
\hline & Crèches & \\
\hline & ECD centres. & \\
\hline Human Resources & Ward Based Outreach Teams. & $\begin{array}{l}\text { Additional community care givers and } \\
\text { nurses. }\end{array}$ \\
\hline Training & Training program and schedules. & $\begin{array}{l}\text { Inclusion of schistosomiasis in IMCI } \\
\text { booklet. }\end{array}$ \\
\hline
\end{tabular}




\section{Discussion}

\subsection{Summary of Findings}

We asked the district health staff members about the operational resources that would be required to implement a schistosomiasis control MDA program for children aged five years old and below in the uMkhanyakude district. The district health staff members reported that there are already existing systems and infrastructure in the district that can facilitate the implementation of such a program. They however, raised concerns on the inadequacy of resources that would be required to ensure the quality and effectiveness of such an MDA program. They recommended that some of the main resources that are required include funding, partnerships, and additional staff. They also highlighted the need for health education in order to ensure sufficient coverage to reduce transmission.

The inadequacy of resources to ensure the success of the program is a funding challenge that is characteristic of many LMIC health systems(Wiseman, Mitton et al., 2016). This funding challenge is worse for financing of healthcare interventions targeting the neglected tropical diseases (NTDs), such as schistosomiasis which affect the poorest of the poor and more often rural communities (Krentel, Gyapong et al., 2017, Pierce, MacDougall et al., 2017; Reed \& McKerrow 2018). Funding needs to be mobilized and sustained(Organization, 2011; Reed \& McKerrow, 2018). The mobilization and sustenance of funds could achieved through global, regional, local partnerships and sources other funding agencies and donors (Molyneux, Bradley et al., 2003; Organization, 2011). WHO has contributed to the donation of PZQ to MDA programs in endemic countries (Hotez, Engels et al., 2010; Stothard, Bustinduy et al., 2014; Cohen, Silva et al., 2016). In South Africa, donated generic praziquantel is not permitted and that makes the use of donated PZQ not an option for funding schistosomiasis control MDA (Magaisa, Taylor et al., 2015) for children aged five years old and below. The health staff interviewed recommended epidemiological data demonstrating the extent of the problem to be used to motivate for the availability of funds to implement a schistosomiasis control MDA program for children aged five years old and below in the district. Epidemiological information guides the allocation of MDA resources to the geographic areas that need the resources (Clements et al., 2006).

The district health staff members were in support of integrating the schistosomiasis control MDA program for children aged five years old and below with existing child health programs. This is in line with the WHO strategy for schistosomiasis control in endemic areas (WHO, 2018). Treatment program integration improves the cost-effectiveness of MDA programs (Goldman et al., 2011) which is very important when financial resources are limited $\mathrm{s}$ as is the case in uMkhanyakude and many other schistosomiasis affected areas. Integration of the schistosomiasis control MDA program with other health programs for this age group will eliminate the costs of duplicate activities that exist between the programs, effectively driving down the cost of running each program. This elimination of duplication was identified by the district health staff members as existing in the combined deworming and vitamin A supplementation program and in the training for the IMCI. The lessons learnt from implementing control MDA programs for schistosomiasis among school-going children can be useful in developing those for schistosomiasis among children aged below five (Mutapi, Rujeni et al., 2011). In some cases the schistosomiasis control MDA programs for school going children have been combined with that for controlling STH because the drugs to treat schistosomiasis and STH can be co-administered (Namwanje, Kabatereine et al., 2011, Lo, Andrews et al., 2016). A schistosomiasis control MDA for children aged five years old and below in the uMkhanyakude could therefore be integrated with the combined deworming and vitamin A supplementation program that is already in place in the district.

The coverage for the vaccination program in the uMkhanyakude District is $84 \%$ while that of the deworming program is $44 \%$ (Health 2017, Health 2018). One of the district health staff members told us that that since some parents do not like the deworming program, health education could assist in improving the acceptability of the program among parents. Other MDA programs such as the school based treatment program in the south coast of KwaZulu-Natal have experienced low coverage because parents did not allow their children to get treated (Magaisa, Taylor et al., 2015). Exaggeration of the side-effects of treatment can cause distrust of MDA programs by some communities (Krentel, Fischer et al., 2013). In some cases, the unacceptability of the MDA programs has been because of people fearing the side effects of the drugs that are used during the MDA programs or/and do not know how to manage or report these side effects (Babu and Kar 2004). For example, in Bangladesh some parents refused their children to be part of a deworming program because of rumours about that the treatment would make their children sick (Nath, Padmawati et al., 2019). The impact of health education is clearly illustrated in the case of Zimbabwe where the high schistosomiasis treatment coverage was attributed to the fact that most parents of the children who received schistosomiasis treatment had knowledge about schistosomiasis(Chimbari 2012). Health education therefore, plays a major role in ensuring sufficient treatment coverage (Habib, Soofi et al., 
2017, Deardorff, Rubin Means et al., 2018). In addition to health education, the availability of resources influences the coverage that can be achieved by an MDA program (Sturrock, Hsiang et al., 2013). This necessitates the need for an understanding of the resource requirements for the program.

\subsection{Comparison With Other Studies}

The unavailability of funds for schistosomiasis control that we report has also been reported by the WHO during an assessment of the resource requirements to expand schistosomiasis control in sub-Saharan Africa (WHO, 2010). Refusal by parents for children to be treated was anticipated to reduce the coverage of an intended schistosomiasis control MDA for children aged five years and below. In the Ugu District of KwaZulu-Natal treatment coverage for a school based program was low because some parents did not want their children to be treated (Randjelovic et al., 2015). Health education was postulated to be a possible solution to low treatment coverage (Randjelovic et al., 2015). The need for the uMkhanyakude Health district to decide on the program with which to integrate a prospective schistosomiasis control MDA for children aged five years old and below resonates with the WHO recommendation that schistosomiasis control MDA programs for this age group should be integrated with existing child health programs (WHO, 2018; Ortu \& Williams, 2017). The need for additional weight scales by the district is in contrast with findings in other countries where a dose pole has been recommended instead of weight scales (Stothard et al., 2011; Palha De Sousa et al., 2014; Sousa-Figueiredo, Betson, \& Stothard, 2012). Measuring scales have been discouraged mainly because scales are expensive and difficult to maintain in the resource limited areas where schistosomiasis is mostly found (Mutapi, 2015). Monitoring and evaluation and additional human resources and training that the district requires were identified as needs in the WHO Regional Strategic Plan for Neglected Tropical Diseases in the African Region 2014-2020 (WHO, 2013).

\subsection{Strengths and Limitations of the Study}

The study explored the views of district health staff of child health programs for children aged five years old and below. The Department of Social Development was not involved in the study because the district health department is the implementing agent for all treatment activities. We sought to find out the resources that are available to implement a schistosomiasis control program for children that are aged five years old and below in the uMkhanyakude District of KwaZulu-Natal. The study data provided overview of the systems that are in place, the resources that are available, the resources that are required and the recommendations of district health staff in relation to the implementation of a schistosomiasis control MDA program for children aged five years old and below.

The strength of this study is that district health systems in South Africa are homogenous throughout the country. As a result, these resource requirements will generally apply to all districts in South Africa where schistosomiasis is endemic. These findings will also apply with minimum amendments to other low and medium income countries (LMICs) where schistosomiasis is endemic. The findings of study, however, have the limitations of not being applicable to places that are not similar to rural South Africa. Schistosomiasis can also be found in some urban and peri-urban areas where the settings are significantly different from the uMkhanyakude Districts.

\section{Conclusion}

The uMkhanyakude district has systems and resources that can be used to implement a schistosomiasis control MDA for children aged five years old and below. These resources are however, insufficient and hence more resources need to be availed to the district for successful implementation of the MDA program. Such an MDA program can be integrated with the vaccination program or the combined deworming and vitamin A supplementation program. Economic evaluations will be necessary to establish the merits of choosing between integrating the schistosomiasis MDA control program for children aged five years old and below with the vaccination program and the deworming and vitamin A Supplementation program. The ideal choice will be one that will be combination of programs that will be more cost effective between the two available options.

\section{Declarations}

\section{Acknowledgements}

The authors would like to acknowledge the College of Health Sciences (CHS) through CHS scholarship program at the University of KwaZulu-Natal for their financial support. This research was commissioned by the National Institute of Health Research using Official Development Assistance (ODA) funding. The views expressed in this publication are those of the author(s) and not necessarily those of the NHS, the National Institute of Health Research, or the Department of Health. We are grateful to the uMkhanyakude Health District for supporting our research activities. 


\section{Availability of Data and Materials}

Data will be made available upon request

\section{Funding}

University of KwaZulu-Natal.

NIHR Global Health Research Unit Tackling Infections To Benefit Africa

British Academy's Early Childhood Development Program.

The above funders contributed to the financing of the materials and travelling that was required to carry out the study.

\section{Authors' Contributions}

MVN conceived the study in collaboration with MC. MVN conducted all the interviews. ITM, MVN, MC and were involved in data analysis and interpretation of results. All the authors revised and approved the final manuscript.

\section{Consent for Publication}

Both authors consent and approve the manuscript for publication.

\section{Ethics Approval and Consent to Participate}

University of KwaZulu-Natal Biomedical Research Ethics Committee (reference number: BE403/18).

KwaZulu-Natal Department of Health Research Committee (reference number NHRD_201809_007).

\section{Competing Interests Statement}

The authors declare no that they have no competing interests.

\section{References}

Babu, B. V., \& Kar, S. K. (2004). Coverage, compliance and some operational issues of mass drug administration during the programme to eliminate lymphatic filariasis in Orissa, India. Tropical Medicine \& International Health, 9(6), 702-709. https://doi.org/10.1111/j.1365-3156.2004.01247.x

Chimbari, M. J. (2012). Enhancing schistosomiasis control strategy for Zimbabwe: building on past experiences. Journal of parasitology research, 2012. https://doi.org/10.1155/2012/353768

Clements, A. C., Lwambo, N. J., Blair, L., Nyandindi, U., Kaatano, G., Kinung'hi, S., ... \& Brooker, S. (2006). Bayesian spatial analysis and disease mapping: tools to enhance planning and implementation of a schistosomiasis control programme in Tanzania. Tropical medicine \& international health, 11(4), 490-503. https://doi.org/10.1111/j.1365-3156.2006.01594.x

Cohen, J. P., Silva, L., Cohen, A., Awatin, J., \& Sturgeon, R. (2016). Progress report on neglected tropical disease drug donation programs. Clinical therapeutics, 38(5), 1193-1204. https://doi.org/10.1016/j.clinthera.2016.02.031

de Souza, D. K., \& Dorlo, T. P. (2018). Safe mass drug administration for neglected tropical diseases. The Lancet Global Health, 6(10), e1054-e1055. https://doi.org/10.1016/S2214-109X(18)30415-7

Deardorff, K. V., Means, A. R., Ásbjörnsdóttir, K. H., \& Walson, J. (2018). Strategies to improve treatment coverage in community-based public health programs: A systematic review of the literature. PLoS neglected tropical diseases, 12(2). https://doi.org/10.1371/journal.pntd.0006211

Goldman, A. S., Brady, M. A., Direny, A., Desir, L., Oscard, R., Vely, J. F., ... \& Baker, M. (2011). Costs of integrated mass drug administration for neglected tropical diseases in Haiti. The American journal of tropical medicine and hygiene, 85(5), 826-833. https://doi.org/10.4269/ajtmh.2011.10-0635

Habib, M. A., Soofi, S., Cousens, S., Anwar, S., ul Haque, N., Ahmed, I., ... \& Bhutta, Z. A. (2017). Community engagement and integrated health and polio immunisation campaigns in conflict-affected areas of Pakistan: a cluster randomised controlled trial. The Lancet Global Health, 5(6), e593-e603. https://doi.org/10.1016/S2214-109X(17)30184-5

Health, D. O. (2017). Province of KwaZulu-Natal Annual Report 2016/2017 Vote 7.

Health, D. O. (2019). South Africa National Master Plan for the Elimination of Neglected Tropical Diseases (2019 - 2025), South African Department of Health. 
Hotez, P. J., Engels, D., Fenwick, A., \& Savioli, L. (2010). Africa is desperate for praziquantel. The Lancet, 376(9740), 496-498. https://doi.org/10.1016/S0140-6736(10)60879-3

Krentel, A., Fischer, P. U., \& Weil, G. J. (2013). A review of factors that influence individual compliance with mass drug administration for elimination of lymphatic filariasis. PLoS neglected tropical diseases, 7(11). https://doi.org/10.1371/journal.pntd.0002447

Krentel, A., Gyapong, M., Mallya, S., Boadu, N. Y., Amuyunzu-Nyamongo, M., Stephens, M., \& McFarland, D. A. (2017). Review of the factors influencing the motivation of community drug distributors towards the control and elimination of neglected tropical diseases (NTDs). PLoS neglected tropical diseases, 11(12). https://doi.org/10.1371/journal.pntd.0006065

KZN-DoH. (2018). UMkhanyakude District Health Plan 2018/19-2020/21.

KZNHealth. (2018). UMkhanyakude Health District. Retrieved January 2019, 2018, from http:/www.kznhealth.gov.za/umkhanyakude.htm.

Lo, N. C., Andrews, J. R., \& Bogoch, I. I. (2016). Improving helminth treatment access: costs and opportunities. The Lancet Infectious Diseases, 16(7), 762-764. https://doi.org/10.1016/S1473-3099(16)30049-4

Magaisa, K., Taylor, M., Kjetland, E. F., \& Naidoo, P. J. (2015). A review of the control of schistosomiasis in South Africa. South African Journal of Science, 111(11-12), 1-6. https://doi.org/10.17159/sajs.2015/20140427

Marchal, B., Van Dormael, M., Pirard, M., Cavalli, A., Kegels, G., \& Polman, K. (2011). Neglected tropical disease (NTD) control in health systems: the interface between programmes and general health services. Acta tropica, 120, S177-S185. https://doi.org/10.1016/j.actatropica.2011.02.017

Molyneux, D. H., Bradley, M., Hoerauf, A., Kyelem, D., \& Taylor, M. J. (2003). Mass drug treatment for lymphatic filariasis and onchocerciasis. Trends in parasitology, 19(11), 516-522. https://doi.org/10.1016/j.pt.2003.09.004

Municipality, U. D. (2018). UMkhanyakude District Municipality. Retrieved 2018, from http://www.ukdm.gov.za/

Mutapi, F., Rujeni, N., Bourke, C., Mitchell, K., Appleby, L., Nausch, N., ... \& Mduluza, T. (2011). Schistosoma haematobium treatment in 1-5 year old children: safety and efficacy of the antihelminthic drug praziquantel. PLoS neglected tropical diseases, 5(5). https://doi.org/10.1371/journal.pntd.0001143

Namwanje, H., Kabatereine, N. B., \& Olsen, A. (2011). The acceptability and safety of praziquantel alone and in combination with mebendazole in the treatment of Schistosoma mansoni and soil-transmitted helminthiasis in children aged 1-4 years in Uganda. Parasitology, 138(12), 1586-1592. https://doi.org/10.1017/S0031182011000138

Nath, T. C., Padmawati, R. S., \& Murhandarwati, E. H. (2019). Barriers and gaps in utilization and coverage of mass drug administration program against soil-transmitted helminth infection in Bangladesh: An implementation research. Journal of infection and public health, 12(2), $205-212$. https://doi.org/10.1016/j.jiph.2018.10.002

Ndayishimiye, O., Ortu, G., Magalhaes, R. J. S., Clements, A., Willems, J., Whitton, J., ... \& Fenwick, A. (2014). Control of neglected tropical diseases in Burundi: partnerships, achievements, challenges, and lessons learned after four years of programme implementation. PLoS neglected tropical diseases, 8(5). https://doi.org/10.1371/journal.pntd.0002684

NDoH. (2014). South Africa Department of Health Strategic Plan for 2014/2019 National Department of Health.

Organization, W. H. (2011). Global plan for artemisinin resistance containment (GPARC).

Osakunor, D. N. M., Mduluza, T., Midzi, N., Chase-Topping, M., Mutsaka-Makuvaza, M. J., Chimponda, T., ... \& Amanfo, S. A. (2018). Dynamics of paediatric urogenital schistosome infection, morbidity and treatment: a longitudinal study among preschool children in Zimbabwe. BMJ global health, 3(2), e000661. https://doi.org/10.1136/bmjgh-2017-000661

Pierce, R. J., MacDougall, J., Leurs, R., \& Costi, M. P. (2017). The future of drug development for neglected tropical diseases: How the european commission can continue to make a difference. Trends in parasitology, 33(8), 581-583. https://doi.org/10.1016/j.pt.2017.04.007

Reed, S. L., \& McKerrow, J. H. (2018). Why funding for neglected tropical diseases should be a global priority. Clinical Infectious Diseases, 67(3), 323-326. https://doi.org/10.1093/cid/ciy349

Savioli, L., Albonico, M., Colley, D. G., Correa-Oliveira, R., Fenwick, A., Green, W., ... \& LoVerde, P. T. (2017). 
Building a global schistosomiasis alliance: an opportunity to join forces to fight inequality and rural poverty. Infectious diseases of poverty, 6(1), 65. https://doi.org/10.1186/s40249-017-0280-8

Stothard, J. R., Bustinduy, A., \& Montresor, A. (2014). Preventive chemotherapy for schistosomiasis and soil-transmitted helminthiasis by cotreatment with praziquantel and albendazole. Clinical Investigation. https://doi.org/10.4155/cli.13.128

Stothard, J. R., Sousa-Figueiredo, J. C., Betson, M., Bustinduy, A., \& Reinhard-Rupp, J. (2013). Schistosomiasis in African infants and preschool children: let them now be treated!. Trends in parasitology, 29(4), 197-205. https://doi.org/10.1016/j.pt.2013.02.001

Sturrock, H. J., Gething, P. W., Ashton, R. A., Kolaczinski, J. H., Kabatereine, N. B., \& Brooker, S. (2011). Planning schistosomiasis control: investigation of alternative sampling strategies for Schistosoma mansoni to target mass drug administration of praziquantel in East Africa. International Health, 3(3), 165-175. https://doi.org/10.1016/j.inhe.2011.06.002

Sturrock, H. J., Hsiang, M. S., Cohen, J. M., Smith, D. L., Greenhouse, B., Bousema, T., \& Gosling, R. D. (2013). Targeting asymptomatic malaria infections: active surveillance in control and elimination. PLoS medicine, 10(6). https://doi.org/10.1371/journal.pmed.1001467

Tebeje, B. M., Harvie, M., You, H., Loukas, A., \& McManus, D. P. (2016). Schistosomiasis vaccines: where do we stand?. Parasites \& vectors, 9(1), 528. https://doi.org/10.1186/s13071-016-1799-4

Tuhebwe, D., Bagonza, J., Kiracho, E. E., Yeka, A., Elliott, A. M., \& Nuwaha, F. (2015). Uptake of mass drug administration programme for schistosomiasis control in Koome Islands, Central Uganda. PLoS One, 10(4). https://doi.org/10.1371/journal.pone.0123673

Turner, H. C., Toor, J., Hollingsworth, T. D., \& Anderson, R. M. (2018). Economic evaluations of mass drug administration: the importance of economies of scale and scope. Clinical Infectious Diseases, 66(8), 1298-1303. https://doi.org/10.1093/cid/cix1001

Webster, J. P., Molyneux, D. H., Hotez, P. J., \& Fenwick, A. (2014). The contribution of mass drug administration to global health: past, present and future. Philosophical Transactions of the Royal Society B: Biological Sciences, 369(1645), 20130434. https://doi.org/10.1098/rstb.2013.0434

WHO. (2000). Needs Assessments. WHO, WHO. Workbook 3.

WHO. (2006). Preventive chemotherapy in human helminthiasis. Manual on preventive chemotherapy.

WHO. (2011). Report of a meeting to review the results of studies on the treatment of schistosomiasis in preschool-age children. W. H. Organisation.

WHO. (2015). Investing to Overcome the Global Impact of Neglected Tropical Diseases: Third WHO Report on Neglected Tropical Diseases 2015. P. P. Holmes, WHO.

WHO. (2018). Schistosomiaisis Control and preventive chemotherapy. 2018, from http://www.who.int/schistosomiasis/strategy/en/.

Wiseman, V., Mitton, C., Doyle-Waters, M. M., Drake, T., Conteh, L., Newall, A. T., ... \& Jan, S. (2016). Using economic evidence to set healthcare priorities in low-income and lower-middle-income countries: a systematic review of methodological frameworks. Health Economics, 25, 140-161. https://doi.org/10.1002/hec.3299

\section{Copyrights}

Copyright for this article is retained by the author(s), with first publication rights granted to the journal.

This is an open-access article distributed under the terms and conditions of the Creative Commons Attribution license (http://creativecommons.org/licenses/by/4.0/). 